\title{
Evaluation of Multimodal Transport in China Based on Hesitation Fuzzy Multiattribute Decision-Making
}

\author{
Bing Han $\mathbb{D}^{1,2}$ Min Wan $\mathbb{D}^{1,2}$ and Yu Zhou ${ }^{1,2}$ \\ ${ }^{1}$ School of Maritime Economics and Management, Dalian Maritime University, Dalian 116000, China \\ ${ }^{2}$ Collaborative Innovation Center for Transport Studies, Dalian Maritime University, Dalian 116000, China \\ Correspondence should be addressed to Bing Han; hanbing0610@163.com and Min Wan; wanmin051810@163.com
}

Received 10 June 2020; Revised 7 September 2020; Accepted 15 September 2020; Published 29 September 2020

Academic Editor: Yi Su

Copyright (c) 2020 Bing Han et al. This is an open access article distributed under the Creative Commons Attribution License, which permits unrestricted use, distribution, and reproduction in any medium, provided the original work is properly cited.

Intermodal transportation, as an efficient form of transport organization, is a key technology and means for the logistics industry to balance transport costs and efficiency. How to deeply analyze the key factors constraining the level of development of multimodal transportation in China, building multimodal transportation development evaluation index system and evaluation model, evaluating comprehensively the multimodal transportation development level in China, and putting forward targeted countermeasures is of great practical significance. Based on the hesitant fuzzy multiattribute decision-making method, this paper analyzes the key factors influencing the level of multimodal transportation development from the perspective of sea-rail intermodal transport and further uses the interval number discretization and likelihood deviation maximization multiattribute decision-making method to construct a mixed-data index evaluation model, which is combined with data from 11 provinces (cities) in China. The study shows that there is a big gap among different provinces (cities) in China concerning the level of multimodal transportation development. Besides, the volume of intermodal container transportation and railway mileage are the core factors affecting the level of multimodal transportation development, and the results of the evaluation model can objectively reflect the level of multimodal transportation development and problems in each province (city). The research results further enrich the theoretical system of intermodal transportation development and provide a reference for the relevant management departments in formulating intermodal transportation plans and policies by putting forward pertinent suggestions in the field of management. In the future, the research direction should include the ecological environment, economic benefits, and other indicators into the evaluation system, expand the research scope of the modes of combined transportation such as public rail transport and public air transport, and improve the applicable scope of the evaluation model and the evaluation capability of specific scenarios.

\section{Introduction}

International Multimodal Transport means the carriage of goods by at least two different modes of transport on the basis of a multimodal transport contract from a place in one country in which the goods are taken in charge by the multimodal transport operator to a place designated for delivery in a different country that was defined by the United Nations Convention in 1980 [1]. According to the technical and economic advantages of the various modes of transportation, logistics transport can be intermodal to improve efficiency and reduce energy consumption and greenhouse gas emissions. The experience of European and American countries shows that intermodal transportation can improve transport efficiency by 30 percent or more, decrease cargo losses and cargo discrepancies by up to 10 percent, reduce the cost of transporting goods, and decrease road traffic congestion by 20 percent or more of transportation costs and up to 50 percent. With the rapid development and continuous improvement of the regional comprehensive transportation network in China, the range of cargo transport options continue to expand, and the multimodal transportation system will be the key direction of future transport logistics development in China. Although certain progress and achievements have been made in the development of multimodal transportation in China, the overall 
level of development is still not high, and there is a large gap compared with Europe and the United States. Therefore, how to deeply analyze the key factors influencing the level of development of intermodal transportation in China and seize the main contradictions in the process of multimodal transportation development has become an important issue in the field of intermodal transportation research in China.

At present, domestic and foreign scholars have carried out researches on the evaluation of the development level of multimodal transport according to different research perspectives and methods, including qualitative, modal transport, stakeholder, and comprehensive evaluation perspectives, etc. Xu et al. [2-4] made qualitative studies on the development level of comprehensive transportation, container multimodal transport synergies, and multimodal transport channels from an overall qualitative perspective. With the development of multimodal transport, the scope of its definition has not been limited to the transnational, gradually formed in accordance with the combination of different modes of transport. Du and Shi and Fang et al. $[5,6]$ evaluated the circulation process and path advantages and disadvantages of container sea-rail combined transport from the perspective of sea-rail combined transport. Berli et al. and Han et al. [7, 8] studied the advantages and disadvantages of sea-land coordinated development and sea-land combined transport network paths from the perspective of sea-land combined transport, respectively. From the perspective of land bridge multimodal transport, several researchers [9-11] studied the operation mechanism and development level of long rail and short truck multimodal transport. From the perspective of sea-air transport, Lu et al. [12] studied the development level of sea-air transport network with airports as transit nodes and international routes from the Far East to Europe and the Far East to Central and South America. The multimodal logistics network formed by different methods is a complex network. They include transportation nodes, transportation connection edges, transit nodes, and transit connection edges [13], which are mainly composed of "service network" (local service network) and "internal operation network" (linehaul operations network) [14]. The complex network involves many stakeholders, decision makers, operations, and planning activities [15], of which freight shippers, carriers, and logistics authorities (planners) are the three main stakeholders [16]. From the perspective of different stakeholders such as shippers, carriers, and governments, the development level evaluation of multimodal transport has different focuses on transportation cost, transportation time, pollutant emission, and transportation emission [17-22]. With the development of the multimodal transport network trend, comprehensive evaluation research on the multimodal transport has also gradually emerged. The evaluation mainly involves in the degree of collaboration between multimodal transport participants and links, system behavior, service quality, evaluation standards, line performance evaluation, etc., as well as environmental costs, operating costs, transportation costs, infrastructure costs, transportation duration, door-to-door transportation, duration of transshipment operations, comfort, safety, reliability, stability, and other indicators [18, 23-27].

It is necessary to face a situation where an attribute may have different evaluation values in the aspect of multimodal transport evaluation. However, neither the expert review method nor the analytic hierarchy process can meet this realistic requirement. Hesitant fuzzy sets allow more than one value for the membership of an element [28], which can effectively deal with the situation where experts are hesitant and difficult to make decisions in the decision-making process. Therefore, it is conducive to building a model to improve the accuracy of the results by introducing hesitant fuzzy multiattribute decision-making to the level of multimodal transport development during the evaluation process. At present, the multiattribute decision-making method is gradually applied in many fields. How to accurately analyze the uncertain information in the decision-making process to make a scientific and reasonable decision is the key to the current research. The fuzzy multiattribute decision-making method is used to solve the problem that, when under environmental data, each decision-making individual in the decision-making group calculates the preference value according to the attributes of the decision-making object with their own preferences and existing knowledge, and then sorts and selects the best. The scientific nature and applicability of the hesitant fuzzy multiattribute decision-making method have been generally proved [29-33].

Therefore, it is of theoretical and practical significance to establish an evaluation index system for the development level of multimodal transport in China, to evaluate the development level of multimodal transport in China objectively and accurately through the actual data, to analyze the key factors restricting the development level of multimodal transport in China in depth, and to propose corresponding countermeasures. As intermodal transportation requires the entire transport process as a whole, combining different modes of transport to form a continuous, optimal, integrated transport network of goods, necessarily involving a certain spatial range by a variety of transport elements, resource integration features, we will introduce the hesitation fuzzy multiattribute decision evaluation method, and on the basis of determining the alternatives and attribute sets for the multimodal transportation level evaluation problem, we will use the Delphi method to obtain the hesitation fuzzy matrix and further use the constructed evaluation model to obtain the comprehensive similarity of each alternative and conduct a comprehensive decision analysis according to the final results to provide countermeasures and suggestions for improving the level of multimodal transportation development.

\section{Research Design}

In view of the above problems, this paper intends to explore and study the evaluation and practice of the development level of multimodal transport from a new perspective and thinking, specifically as follows: (1) study the optimization of multimodal transport network from the perspective of comprehensive development level evaluation; (2) deeply 
analyze and examine the factors affecting the development of multimodal transport and build an evaluation index system; (3) study the mixed multiattribute index decision-making based on the combination of accurate data and interval type data; (4) the evaluation model is constructed, and the objective data of the development status of multimodal transport is used to analyze and verify the feasibility of the algorithm and give the targeted countermeasures for the development of multimodal transport.

2.1. Index Construction. The design of the evaluation index system should follow the principles of scientificity, feasibility, and objectivity. That is to say, index construction should be based on scientific and reasonable analysis, be operable and easy to operate, and reflect objective facts as much as possible. Combining and analyzing relevant literature, Yang [34] used the system engineering method to build a multimodal transport performance evaluation index system including mobility and reliability, safety, environmental management, cost efficiency, and economic development. Zhu et al. [35] set up the evaluation index system of container multimodal transport efficiency level from three aspects of system efficiency, technical efficiency, and operation efficiency. Combined with the development mission of China's multimodal transport, based on the analysis of references, following the principles of science, feasibility, and objectivity, the evaluation indexes of regional multimodal transport including production capacity, policy strength, and service quality are selected. According to the data types of precise and interval indexes, the indexes can be divided into quantitative indexes and qualitative indexes. According to the changing trend of index data value and the performance trend of the evaluation object in this aspect, the index can be divided into benefit index and cost index [36]. The evaluation index system of regional multimodal transport development level is obtained as shown in Table 1.

For the fuzziness index, the scoring method of 1-10 points is used for measurement, and the following nine intervals are used for the division of 1-10 points with reference to the scoring method of the Likert scale. The corresponding descriptions of different interval standards are shown in Table 2.

2.2. Model Construction. To evaluate the development level of multimodal transport in province (city), this paper not only considers the quantitative indicators such as the volume of container sea-rail transport, the proportion of container throughput, railway operating mileage, the amount of government investment, and the number of multimodal transport demonstration projects but also considers the qualitative indicators such as the business level, service state, and technical level that reflect the service quality of multimodal transport. Therefore, it is necessary to analyze the mixed data composed of precise data and interval data. Therefore, this paper uses the method of maximizing the deviation between interval separation degree and scheme attribute, finds the optimal objective weight vector and the comprehensive index value of each scheme through the decision matrix, establishes the mixed possibility complementary judgment matrix, and obtains the sorting vector and sorts according to the scheme of component size to get the optimal scheme.

(1) Building decision matrix

Set $X=\left\{x_{1}, x_{2}, \ldots, x_{n}\right\}$ as the evaluation object set, $U=\left\{u_{1}, u_{2}, \ldots, u_{m}\right\}$ as the evaluation index set , $W=\left\{w_{1}, w_{2}, \ldots, w_{m}\right\}^{T}$ as the weight vector of the evaluation index, $w_{i} \geq 0, w_{i} \in\left[w_{i}^{l}, w_{i}^{u}\right], \sum_{i=1}^{m} w_{i}=1$. This paper uses an evaluation index $u_{j} \in U$ to evaluate evaluation object $x_{i} \in X$ and get the accurate evaluation value $m_{1}$ and interval evaluation value $m_{2}\left(m_{1}+m_{2}=m\right)$. Furthermore, the decision matrix $A=\left(a_{i j}\right)_{n \times m}=\left[\left(a_{i j}\right)_{n \times m_{1}},\left(a_{i j}^{l}, a_{i j}^{u}\right)_{n \times m_{2}}\right]$ can be obtained by applying all the evaluation indexes to evaluate all the evaluation objects.

(2) Normalization of decision matrix

As mentioned above, indicators can be divided into accurate type (Quantitative) and interval type (Qualitative) according to the type of indicator data value. At the same time, indicators can be divided into cost type and benefit type according to the change of indicator value and the changing trend of evaluation results under the indicator. Therefore, indicator types can be divided into four types: quantitative cost type, quantitative benefit type, qualitative cost type, and qualitative benefit type. On the basis of references [37], different types of data are standardized as follows.

The standardized formula of quantitative cost index data:

$$
r_{i j}=\frac{\min _{j} a_{i j}}{a_{i j}}, \quad j \in N .
$$

The standardized formula of quantitative benefit index data:

$$
r_{i j}=\frac{a_{i j}}{\max _{j} a_{i j}}, \quad j \in N .
$$

The standardized formula of qualitative cost index data:

$$
\left\{\begin{array}{l}
r_{i j}^{l}=\frac{\left(1 / a_{i j}^{u}\right)}{\sqrt{\sum_{j=1}^{n}\left(1 / a_{i j}^{l}\right)^{2}}}, \\
r_{i j}^{u}=\frac{\left(1 / a_{i j}^{l}\right)}{\sqrt{\sum_{j=1}^{n}\left(1 / a_{i j}^{u}\right)^{2}}},
\end{array} \quad j \in N .\right.
$$

The standardized formula of qualitative benefit index data: 
TABLE 1: Evaluation index system of regional multimodal transport development level.

\begin{tabular}{|c|c|c|c|}
\hline First level indicators & $\begin{array}{l}\text { Secondary } \\
\text { index }\end{array}$ & Three-level indicators & Type \\
\hline \multirow{8}{*}{$\begin{array}{l}\text { The development level of multimodal } \\
\text { transport }\end{array}$} & \multirow{3}{*}{ Throughput } & Sea-rail intermodal container volume/TEU (X1) & $\begin{array}{l}\text { Quantitative index of } \\
\text { benefit type }\end{array}$ \\
\hline & & $\begin{array}{l}\text { Proportion of intermodal container throughput } \\
\text { (X2) }\end{array}$ & $\begin{array}{l}\text { Quantitative index of } \\
\text { benefit type }\end{array}$ \\
\hline & & Total mileage of railway operation/kilometre (X3) & $\begin{array}{l}\text { Quantitative index of } \\
\text { benefit type }\end{array}$ \\
\hline & \multirow{2}{*}{ Policy strength } & Government investment/100 million yuan (X4) & $\begin{array}{l}\text { Quantitative index of } \\
\text { benefit type }\end{array}$ \\
\hline & & $\begin{array}{c}\text { Number of multimodal transport demonstration } \\
\text { projects/unit (X5) }\end{array}$ & $\begin{array}{l}\text { Quantitative index of } \\
\text { benefit type }\end{array}$ \\
\hline & \multirow{3}{*}{ Service quality } & Business level (X6) & $\begin{array}{l}\text { Qualitative index of benefit } \\
\text { type }\end{array}$ \\
\hline & & Service attitude (X7) & $\begin{array}{l}\text { Qualitative index of benefit } \\
\text { type }\end{array}$ \\
\hline & & Technical level (X8) & $\begin{array}{l}\text { Qualitative index of benefit } \\
\text { type }\end{array}$ \\
\hline
\end{tabular}

TABLe 2: Fuzzy interval division standard and description.

\begin{tabular}{lccc}
\hline $\begin{array}{l}\text { Interval } \\
\text { standard }\end{array}$ & \multicolumn{3}{c}{ Description of qualitative index interval } \\
& Business level & $\begin{array}{l}\text { Service } \\
\text { attitude }\end{array}$ & Technical level \\
\hline$[1,2]$ & Terrible & Terrible & Terrible \\
{$[2,3]$} & Very poor & Very poor & Very poor \\
{$[3,4]$} & Quite poor & Quite poor & Quite poor \\
{$[4,5]$} & Poor & Poor & Poor \\
{$[5,6]$} & General & General & General \\
{$[6,7]$} & Good & Good & Good \\
{$[7,8]$} & Quite good & Quite good & Quite good \\
{$[8,9]$} & Very good & Very good & Very good \\
{$[9,10]$} & Great & Great & Great \\
\hline
\end{tabular}

$$
\left\{\begin{array}{l}
r_{i j}^{l}=\frac{a_{i j}^{l}}{\sqrt{\sum_{j=1}^{n}\left(a_{i j}^{u}\right)^{2}}}, \\
r_{i j}^{u}=\frac{a_{i j}^{u}}{\sqrt{\sum_{j=1}^{n}\left(a_{i j}^{l}\right)^{2}}},
\end{array} \quad j \in N .\right.
$$

Here, $N=\{1,2, \ldots, n\}$. Based on formulas $(1)-(4)$, the decision matrix $A=\left(a_{i j}\right)_{n \times m}=\left[\left(a_{i j}\right)_{n \times m_{1}}\right.$, $\left.\left(a_{i j}^{l}, a_{i j}^{u}\right)_{n \times m_{2}}\right]$ can be transformed into a normalized matrix $R=\left(r_{i j}\right)_{n \times m}=\left[\left(r_{i j}\right)_{n \times m_{1}},\left(r_{i j}^{l}, r_{i j}^{u}\right)_{n \times m_{2}}\right]$.

(3) Weight vector solution

The weight vector $W$ solution follows the idea of maximizing the overall deviation value of the evaluation object under the evaluation index set. According to the definition of interval distance in literature [38], we can set interval number $a=\left[a^{l}, a^{u}\right], \quad b=\left[b^{l}, b^{u}\right] \quad$ and regard $D(a, b)=\|a-b\|=\left|b^{l}-a^{l}\right|+\left|b^{u}-a^{u}\right|$ as the distance degree of interval number $a, b$. Under a certain index $u_{j} \in U$, the deviation value of evaluation object $x_{i}$ and other evaluation objects are expressed by $L_{i j}(w)$, while $L_{i}(w)$ represents the sum of deviation values of all the evaluation objects:

$$
\begin{array}{r}
L_{i j}(w)=\sum_{k=1}^{n}\left(\left|r_{i j}^{l}-r_{k j}^{l}\right|+\left|r_{i j}^{u}-r_{k j}^{u}\right|\right) w_{j}, \quad i \in N, j \in M, \\
L_{i}(w)=\sum_{i=1}^{n} L_{i j}(w)=\sum_{i=1}^{n} \sum_{k=1}^{n}\left(\left|r_{i j}^{l}-r_{k j}^{l}\right|+\left|r_{i j}^{u}-r_{k j}^{u}\right|\right) w_{j}, \\
i \in N .
\end{array}
$$

Furthermore, build the overall deviation function of the evaluation object under all indexes:

$L(w)=\sum_{j=1}^{m} L_{i}(w)=\sum_{j=1}^{m} \sum_{i=1}^{n} \sum_{k=1}^{n}\left(\left|r_{i j}^{l}-r_{k j}^{l}\right|+\left|r_{i j}^{u}-r_{k j}^{u}\right|\right) w_{j}$.

To solve the weight vector $W$ is to solve the maximum $L(w)$ value problem under certain constraints. The solution equation is as follows:

$$
\begin{array}{cc}
\max & L(w)=\sum_{j=1}^{m} \sum_{i=1}^{n} \sum_{k=1}^{n}\left(\left|r_{i j}^{l}-r_{k j}^{l}\right|+\left|r_{i j}^{u}-r_{k j}^{u}\right|\right) w_{i} \\
\text { s.t. } \quad & w=\left(w_{1}, w_{2}, \ldots, w_{m}\right)^{T}, \\
& w_{j} \in\left[w_{j}^{l}, w_{j}^{u}\right], w_{j} \geq 0, \sum_{j=1}^{m} w_{j}=1 .
\end{array}
$$


(4) Solution of the comprehensive index value

The comprehensive index value $z_{i}$ is the sum of the evaluation values of each province (city) in the evaluation system of the multimodal transport development level index. The calculation formula is as follows:

$$
z_{i}=\sum_{j=1}^{m} r_{i j} w_{j}, \quad j \in M,
$$

where $w_{j}$ is the weight of the jth index, $r_{i j}$ is the evaluation value in the normalized matrix $R=\left(r_{i j}\right)_{n \times m}=\left[\left(r_{i j}\right)_{n \times m_{1}},\left(r_{i j}^{L}, r_{i j}^{U}\right)_{n \times m_{2}}\right]$.

(5) Constructing the complementary matrix of possibility degree

According to formula (9), the comprehensive index of each province (city) is interval data. It is necessary to introduce the concept of interval comparison possibility to compare interval numbers. The definition of interregional probability in the cited references is as follows [39]:

Let $a=\left[a^{l}, a^{u}\right], \quad b=\left[b^{l}, b^{u}\right]$, and $S(a)=a^{u}-a^{l}$, $S(b)=b^{u}-b^{l}$; then,

$$
P(a \geq b)=\frac{\max \left\{0, S(a)+S(b)-\max \left(a^{u}-b^{l}, 0\right)\right\}}{S(a)+S(b)} .
$$

Define the possibility that $P(a \geq b)$ is $a \geq b$. In this definition, $P(a \geq b)$ has the following properties:

(a) $P(a \geq b)+P(b \geq a)=1$

(b) If $P(a \geq b)=P(b \geq a)$, then $P(a \geq b)=$ $P(b \geq a)=(1 / 2)$

(c) If $a^{U} \leq b^{L}$, then $P(a \geq b)=0$; if $a^{L} \geq b^{U}$, then $P(a \geq b)=1$ (d) For three interval numbers $a, b, c$, if $a \geq b$, then $P(a \geq c) \geq P(b \geq c)$

Based on formula (10), we can get the complementary judgment matrix of possibility degree $P=\left(P_{i j}\right) n \times n$.

(6) Sorting vector solution

On the basis of the complementary judgment matrix of the possibility degree of each province (city), the calculation formula of the sequence vector $h=\left(h_{1}, h_{2}, \ldots, h_{n}\right)^{T}$ of the fuzzy complementary judgment matrix is obtained [38]:

$$
h_{i}=\frac{\left(\sum_{j=1}^{n} P_{i j}+(n / 2)-1\right)}{n(n-1)} .
$$

The ranking vector of probability matrix $\mathrm{P}$ is obtained, and the development level of multimodal transport in each province is ranked according to the component size of the ranking vector.

\section{Empirical Analysis}

From five aspects of production, policy, and service, this paper makes an empirical analysis on the development level of rail sea intermodal transport in 18 provinces (cities) in China, obtains the original data through the port Yearbook, provincial Yearbook, annual report, and other documents, and constructs the decision matrix as shown in Table 3 by applying the evaluation index system in Table 1 .

According to step 2, the benefit and cost indicators as well as formulas (1)-(6), the decision matrix $A$ can be transformed into a normalization matrix as shown in Table 4.

The single objective optimization model is established by using the idea of interval distance and a maximum deviation of the scheme index:

$$
\begin{aligned}
& \max D(w)=16.6 w_{1}+20.98 w_{2}+20.46 w_{3}+11.89 w_{4}+17 w_{5}+3.36 w_{6}+2.94 w_{7}+2.90 w_{8} \\
& \text { s.t. } 0.12 \leq w_{1} \leq 0.18,0.10 \leq w_{2} \leq 0.16,0.10 \leq w_{3} \leq 0.18,1.12 \leq w_{4} \leq 0.16,0.08 \leq w_{5} \leq 0.14, \\
& \quad 0.08 \leq w_{6} \leq 0.14,0.08 \leq w_{7} \leq 0.14,0.06 \leq w_{8} \leq 0.12, \\
& \quad \sum_{i=1}^{8} w_{i}=1, \quad w_{i} \geq 0, i \in(1,2,3, \ldots, 8) .
\end{aligned}
$$

Using Python 2.7 software to solve the model, the optimal weight vector is $W=(0.18,0.16,0.18,0.12,0.14,0.08$, $0.08,0.06)$.
According to formula (9), the comprehensive index value $z_{j}(w)(j \in N)$ is as follows: 
TABle 3: Decision matrix.

\begin{tabular}{|c|c|c|c|c|c|c|c|c|}
\hline & (X1) & $(\mathrm{X} 2)(\%)$ & (X3) & (X4) & (X5) & (X6) & (X7) & $(\mathrm{X} 8)$ \\
\hline Shanghai (A) & 15.56 & 0.39 & 465.10 & 170.00 & 1 & {$[8,9]$} & {$[8,9]$} & {$[7,8]$} \\
\hline Shandong (B) & 63.81 & 2.49 & 5726.40 & 118.00 & 2 & {$[7,8]$} & {$[8,9]$} & {$[8,9]$} \\
\hline Jiangsu (C) & 25.17 & 1.46 & 2816.40 & 89.24 & 3 & {$[7,8]$} & {$[7,8]$} & {$[8,9]$} \\
\hline Liaoning (D) & 111.92 & 5.74 & 5914.70 & 45.90 & 4 & {$[8,9]$} & {$[7,8]$} & {$[8,9]$} \\
\hline Fujian (E) & 16.87 & 1.08 & 3191.40 & 106.20 & 1 & {$[6,7]$} & {$[7,8]$} & {$[7,8]$} \\
\hline Guangdong (F) & 43.26 & 0.69 & 4200.70 & 85.20 & 3 & {$[7,8]$} & {$[8,9]$} & {$[7,8]$} \\
\hline Guangxi (G) & 29.76 & 4.91 & 5191.40 & 40.63 & 1 & {$[7,8]$} & {$[6,7]$} & {$[7,8]$} \\
\hline Hainan $(\mathrm{H})$ & 0.86 & 0.41 & 1033.40 & 181.00 & 1 & {$[6,7]$} & {$[7,8]$} & {$[6,7]$} \\
\hline Hebei (I) & 20.60 & 5.50 & 7162.00 & 70.70 & 3 & {$[7,8]$} & {$[7,8]$} & {$[7,8]$} \\
\hline Tianjin $(\mathrm{J})$ & 34.93 & 2.32 & 1148.90 & 9.25 & 1 & {$[7,8]$} & {$[8,9]$} & {$[7,8]$} \\
\hline Zhejiang (K) & 42.64 & 1.55 & 2624.00 & 124.00 & 2 & {$[8,9]$} & {$[7,8]$} & {$[7,8]$} \\
\hline
\end{tabular}

TABLE 4: Standardized decision matrix.

\begin{tabular}{|c|c|c|c|c|c|c|c|c|}
\hline & $(\mathrm{X} 1)$ & $(\mathrm{X} 2)$ & (X3) & $(\mathrm{X} 4)$ & (X5) & (X6) & (X7) & (X8) \\
\hline Shanghai (A) & 0.14 & 0.07 & 0.06 & 0.05 & 0.25 & {$[0.30,0.38]$} & {$[0.29,0.37]$} & {$[0.26,0.33]$} \\
\hline Shandong (B) & 0.57 & 0.43 & 0.80 & 0.08 & 0.50 & {$[0.26,0.34]$} & {$[0.29,0.37]$} & {$[0.29,0.38]$} \\
\hline Jiangsu (C) & 0.22 & 0.25 & 0.39 & 0.10 & 0.75 & {$[0.26,0.34]$} & {$[0.25,0.33]$} & {$[0.29,0.38]$} \\
\hline Liaoning (D) & 1.00 & 1.00 & 0.83 & 0.20 & 1.00 & {$[0.30,0.38]$} & {$[0.25,0.33]$} & {$[0.29,0.38]$} \\
\hline Fujian (E) & 0.15 & 0.19 & 0.45 & 0.09 & 0.25 & {$[0.22,0.30]$} & {$[0.25,0.33]$} & {$[0.26,0.33]$} \\
\hline Guangdong (F) & 0.39 & 0.12 & 0.59 & 0.11 & 0.75 & {$[0.26,0.34]$} & {$[0.29,0.37]$} & {$[0.26,0.33]$} \\
\hline Guangxi $(\mathrm{G})$ & 0.27 & 0.86 & 0.72 & 0.23 & 0.25 & {$[0.26,0.34]$} & {$[0.22,0.29]$} & {$[0.26,0.33]$} \\
\hline Hainan $(\mathrm{H})$ & 0.01 & 0.07 & 0.14 & 0.05 & 0.25 & {$[0.22,0.30]$} & {$[0.25,0.33]$} & {$[0.22,0.29]$} \\
\hline Hebei (I) & 0.18 & 0.96 & 1.00 & 0.13 & 0.75 & {$[0.26,0.34]$} & {$[0.25,0.33]$} & {$[0.26,0.33]$} \\
\hline Tianjin (J) & 0.31 & 0.40 & 0.16 & 1.00 & 0.25 & {$[0.26,0.34]$} & {$[0.29,0.37]$} & {$[0.26,0.33]$} \\
\hline Zhejiang (K) & 0.38 & 0.27 & 0.37 & 0.07 & 0.50 & {$[0.30,0.38]$} & {$[0.25,0.33]$} & {$[0.26,0.33]$} \\
\hline
\end{tabular}

$$
\begin{aligned}
& Z_{\mathrm{A}}(w)=[0.2687,0.2839], \\
& Z_{\mathrm{B}}(w)=[0.4568,0.4750], \\
& z_{\mathrm{C}}(w)=[0.3252,0.3458], \\
& z_{\mathrm{D}}(w)=[0.7118,0.7324], \\
& z_{\mathrm{E}}(w)=[0.2355,0.2531], \\
& z_{\mathrm{F}}(w)=[0.3738,0.3890], \\
& z_{\mathrm{G}}(w)=[0.4291,0.4477], \\
& z_{\mathrm{H}}(w)=[0.1325,0.1477], \\
& z_{\mathrm{I}}(w)=[0.5429,0.5605], \\
& z_{\mathrm{J}}(w)=[0.3661,0.3813], \\
& z_{\mathrm{K}}(w)=[0.3157,0.3333] .
\end{aligned}
$$

Calculate the possibility of the comparison of the comprehensive index values of multimodal transport in different regions and establish the possibility matrix:

$$
p=\left\{\begin{array}{ccccccccccc}
0.5 & 0 & 0 & 0 & 1 & 0 & 0 & 1 & 0 & 0 & 0 \\
1 & 0.5 & 1 & 0 & 1 & 1 & 1 & 1 & 0 & 1 & 1 \\
1 & 0 & 0.5 & 0 & 1 & 0 & 0 & 1 & 0 & 0 & 1 \\
1 & 1 & 1 & 0.5 & 1 & 1 & 1 & 1 & 1 & 1 & 1 \\
0 & 0 & 0 & 0 & 0.5 & 0 & 0 & 1 & 0 & 0 & 0 \\
1 & 0 & 1 & 0 & 1 & 0.5 & 0 & 1 & 0 & 0.5 & 1 \\
1 & 0 & 1 & 0 & 1 & 1 & 0.5 & 1 & 0 & 1 & 1 \\
0 & 0 & 0 & 0 & 0 & 0 & 0 & 0.5 & 0 & 0 & 0 \\
1 & 1 & 1 & 0 & 1 & 1 & 1 & 1 & 0.5 & 1 & 1 \\
1 & 0 & 1 & 0 & 1 & 0.5 & 0 & 1 & 0 & 0.5 & 1 \\
1 & 0 & 0 & 0 & 1 & 0 & 0 & 1 & 0 & 0 & 0.5
\end{array}\right\} .
$$

According to formula (11), the order vector of probability $p$ is $W=(0.0636,0.1182,0.0818,0.1364,0.0545,0.0955$, $0.1091,0.0455,0.1273,0.0955,0.0727)$. 
The right ordering vector $w$ and the possibility degree in proof $\mathrm{P}$ are obtained, and the ordering of interval number $z_{j}(w)$ is as follows:

$$
Z_{\mathrm{D}}(w) \underset{1}{\geq} Z_{\mathrm{I}}(w) \underset{1}{\geq} Z_{\mathrm{B}}(w) \underset{1}{\geq} Z_{\mathrm{G}}(w) \underset{1}{\geq} Z_{\mathrm{J}}(w) \underset{0.5}{\geq} Z_{\mathrm{F}}(w) \underset{1}{\geq} Z_{\mathrm{C}}(w) \underset{1}{\geq} Z_{\mathrm{K}}(w) \underset{1}{\geq} Z_{\mathrm{A}}(w) \underset{1}{\geq} Z_{\mathrm{E}}(w) \geq Z_{\mathrm{H}}(w)
$$

According to the size of $z_{j}(w)(i=1,2,3, \ldots, 8)$ value, the provinces (municipalities) are ranked as follows:

$$
D \succ I \succ_{1} B \succ C \succ_{1} J \underset{0.5}{\succ} F \succ_{1} C \succ_{1} K \succ_{1} A \succ_{1} E \succ_{1} H .
$$

It shows that Liaoning is the province with the highest level of multimodal transport development, followed by Hebei, Shandong, and Guangxi, with the advantage probability of $100 \%$. Tianjin is ranked fifth with a $50 \%$ advantage over Guangdong, followed by Guangdong, Jiangsu, Zhejiang, Shanghai, Fujian, and Hainan, with the advantage probability of $100 \%$. According to the weight of the indexes in the model, we can see sea-rail transport capacity, intermodal container throughput ratio, and railway mileage are the main influence factors affecting the development of regional sea-rail transport, Liaoning with good infrastructure foundation, a higher rate of cargo containers, and high proportion therefore ranked first, but in the aspect of government investment and personnel service attitude in Liaoning is yet to be promoted. Hebei, Shandong, Guangxi, and Tianjin all have a good logistics network foundation and container freight volume, and at the same time, have different degrees of problems in the proportion of container combined transportation, multimodal transportation demonstration project, business level, and so on. Guangdong, Jiangsu, Zhejiang, Shanghai, Fujian, and Hainan are at a disadvantage compared with the northern provinces in searail combined transport due to the developed sea transport and water systems around them. Meanwhile, the above provinces should fully recognize their own advantages and disadvantages and develop sea-rail, sea-land, water-to-water, and other combined transport modes in an integrated manner.

\section{Conclusion}

Based on the perspective of sea-rail intermodal transportation, this paper deeply analyzes the key indicators that influence the level of intermodal transport development, constructs a mixed multievaluation index system which includes precise and interval data, and evaluates the level of multimodal transport development in 11 provinces (cities) in China by using the fuzzy multiattribute decision method model.

The following conclusions are drawn: (1) The evaluation method of regional multimodal transportation development level is studied from the perspective of sea-rail multimodal transportation, and the intermodal transportation development level evaluation index system based on sea-rail multimodal transport is constructed through the analysis of relevant literature and a questionnaire survey of experts and industry insiders. (2) The application of the multiattribute decision model solves the problem of unifying data standards for multiple indicators of intermodal transportation and provides new ideas for obtaining more objective and comprehensive evaluation results. (3) Based on the perspective of sea-rail intermodal transportation, we solve the weights of mixed evaluation indexes and obtain the key factors for the development of intermodal transportation in each province (city) as cargo containerization, containerized sea-rail intermodal transportation volume, and railway mileage, which provide the development direction for each region to improve the level of intermodal transport. (4) According to objective and real data, qualitative and quantitative index data will be comprehensively evaluated, and it is found that the development level of multimodal transportation in each province (city) of China. It is uneven and problematic, and more targeted responses need to be developed.

Based on the research results, the following suggestions are proposed: First, for government departments, it is necessary to coordinate the development and construction of multimodal transport in various regions, increase investment in multimodal transport infrastructure, guide the standardized development of industry regulations and technical standards, and break information barriers to promote efficient information transmission. Second, multimodal transport operators should fully understand the key factors affecting the development of their own transport capacity and concentrate limited resources to strengthen the core competitiveness. Third, for shippers, when choosing the route of multimodal transport service, it is necessary to give full consideration to the hard targets of the carrier in terms of containerization of goods, intermodal transport, intermodal transport operating mileage, etc., so as to ensure the efficient and safe delivery of goods. The research in this paper also needs to further improve the evaluation index system, such as increasing the evaluation indexes of ecological environment and economic benefits, so as to be able to more objectively and comprehensively evaluate the level of intermodal transportation development. Future research should expand intermodal transportation modes, such as intermodal road-rail and road-air so that the model can be adapted to more regional scales and enhance the applicability of the model.

\section{Data Availability}

The data used to support the findings of this study are available from the corresponding author upon request. 


\section{Conflicts of Interest}

The authors declare no conflicts of interest.

\section{Acknowledgments}

This work was supported by the National Key Research and Development Project (Grant No. 2019YFB1600401), Youth Program of National Natural Science Foundation of China (Grant no. 71503029), and the State Key Program of National Natural Science of China (Grant no. 71831002).

\section{References}

[1] Kam, B. Liu, and Tanlin, "The development trend of international multimodal transport and China's countermeasures," China's Circulation Economy, vol. 4, no. 12, pp. 17-20, 2019.

[2] Y. Xu, B. Su, L. Zhang et al., "Study on comprehensive evaluation and adaptability of regional economy and transportation system development in Shaanxi Province," Ecological Economy, vol. 32, no. 3, pp. 108-112, 2016.

[3] H. Park, H. Liu, and B. Zhang, "Comprehensive evaluation of container multimodal transport coordination capability," China Navigation, vol. 36, no. 4, pp. 125-129, 2013.

[4] Z. Jin, Q. Xu, and M. Chen, "Evaluation and empirical study of intermodal container transport channels," China Science and Technology Paper Online, vol. 6, no. 5, pp. 390-394, 2011.

[5] Q. Du and X. Shi, Sea-Rail Combined Transport Model Based on Queuing Theory, IEEE, Piscataway, NJ, USA, 2016.

[6] X. Fang, C. Cao, Z. Chen et al., "Using mixed methods to design service quality evaluation indicator system of railway container multimodal transport," Science Progress, vol. 103, no. 1, Article ID 003685041989049, 2019.

[7] J. Berli, M. Bunel, and C. Ducruet, "Sea-land interdependence in the global maritime network: the case of Australian port cities," Networks and Spatial Economics, vol. 18, no. 3, pp. 447-471, 2018.

[8] X. Han, Y. Wang, and Z. Jin, "Study on the optimization of land sea intermodal transportation path of containers around the Bohai Sea considering multi tasks," Logistics Engineering and Management, vol. 41, no. 3, pp. 79-82, 2019.

[9] Y. Wiseman and Y. Giat, "Red sea and Mediterranean Sea land bridge via Eilat," World Review of Intermodal Transportation Research, vol. 5, no. 4, pp. 353-368, 2015.

[10] V. N. Filina, "Russian market of transport services in international container transportation," Studies on Russian Economic Development, vol. 23, no. 2, pp. 153-161, 2012.

[11] R. Pomfret, "The Eurasian land bridge: linking regional value chains along the new silk road," Cambridge Journal of Regions, Economy and Society, vol. 12, no. 1, pp. 45-56, 2019.

[12] M. Lu, Y. Chen, R. Morphet et al., "The spatial competition between containerised rail and sea transport in Eurasia," Palgrave Communications, vol. 5, no. 1, Article ID 122, 2019.

[13] Z. He, J.-N. Guo, and J.-X. Xu, "Cascade failure model in multimodal transport network risk propagation," Mathematical Problems in Engineering, vol. 2019, no. 2, 7 pages, Article ID 3615903, 2019.

[14] G. Wang, "Study on international logistics operation mode based on multimodal transport," China Circulation Economy, vol. 2003, no. 5, pp. 20-22, 2003.

[15] T. G. Crainic, G. Perboli, and M. Rosano, "Simulation of intermodal freight transportation systems: a taxonomy,"
European Journal of Operational Research, vol. 270, no. 2, pp. 401-418, 2018.

[16] D. Sheng, X. C. Li, and X. D. Fu, "Modeling the effects of unilateral and uniform emission regulations under shipping company and port competition," Transportation Research Part E: Logistics and Transportation Review, vol. 101, no. 5, pp. 99-114, 2017.

[17] A. Gillen, J. Yee, and B. Golden, "Scheduling players in team competitions: theory and computational results," American Journal of Mathematical and Management Sciences, vol. 3, no. 2, pp. 89-119, 1983.

[18] Y. Su and T. Li, "Simulation analysis of knowledge transfer in a knowledge alliance based on a circular surface radiator model," Complexity, vol. 2020, no. 8, 27 pages, Article ID 4301489, 2020.

[19] G. Lanza, T. G. Crainic, W. Rei, and N. Ricciardi, “A study on travel time stochasticity in service network design with quality targets," in Proceedings of the 9th International Conference on Computational Logistics, ICCL 2018, Vietri sul Mare, Italy, October 2018.

[20] J. E. Holler Branco, D. H. Branco, E. M. De Aguiar, J. V. Caixeta Filho, and L. Rodrigues, "Study of optimal locations for new sugarcane mills in Brazil: application of a MINLP network equilibrium model," Biomass \& Bioenergy, vol. 127, no. 8, pp. 105241-105249, 2019.

[21] Y. Sun, X. Li, X. Liang, and C. Zhang, "A bi-objective fuzzy credibilistic chance-constrained programming approach for the hazardous materials road-rail multimodal routing problem under uncertainty and sustainability," Sustainability, vol. 11, no. 9, Article ID 2577, 2019.

[22] J. Wan and S. Wei, "Multi-objective multimodal transportation path selection based on hybrid algorithm," Journal of Tianjin University, vol. 2019, no. 3, pp. 285-292, 2019.

[23] X. Fang, Z. Ji, Z. Chen, and W. Chen, "Synergy degree evaluation of container multimodal transport system," Sustainability, vol. 12, no. 4, Article ID 1487, 2020.

[24] M. Friedrich, "Evaluating the service quality in multimodal transport networks," Transportation Research Procedia, vol. 15, pp. 100-112, 2016.

[25] S. Stoilova and L. Kunchev, "Study of criteria for evaluation of transportation with intermodal transport," "Study of criteria for evaluation of transportation with intermodal transport," in Proceedings of the 16th International Scientific Conference: Engineering for Rural Development, L. Malinovska and V. Osadcuks, Eds., Latvia Univ Agriculture, Faculty Engineering, Inst Mechanics, Jelgava, Latvia, pp. 349-357, May 2017.

[26] B. Di Pierro, G. Iacobellis, B. Turchiano et al., Performance Assessment for Intermodal Transportation Systems: A Case Study, IEEE, New York, NY, USA, 2017.

[27] Q. Wang, J. Chen, M. Tseng, H. M. Luan, and M. H. Ali, "Modelling green multimodal transport route performance with witness simulation software," Journal of Cleaner Production, vol. 248, Article ID 119245, 2020.

[28] C. Cui, X. Zhu, Y. Ren et al., "Evaluation of agricultural modernization level based on hesitant fuzzy multi-attribute decision-making method," Management Review, vol. 31, no. 11, pp. 195-201, 2019.

[29] J. Mao, Q. Sun, and K. Gui, "Study on hesitant fuzzy multiattribute quality evaluation based on surface defect information of autobody panels," Mathematical Problems in Engineering, vol. 2020, Article ID 8203254, 10 pages, 2020.

[30] L. Xu, Y. Liu, and H. Liu, "Some improved $q$-Rung orthopair fuzzy aggregation operators and their applications to 
multiattribute group decision-making," Mathematical Problems in Engineering, vol. 2019, no. 2, 18 pages, Article ID 2036728, 2019.

[31] Y. Liu, J. Liu, and Y. Qin, "Dynamic intuitionistic fuzzy multiattribute decision making based on evidential reasoning and MDIFWG operator," Journal of Intelligent \& Fuzzy Systems, vol. 36, no. 6, pp. 5973-5987, 2019.

[32] S.-M. Chen and W.-H. Han, "Multiattribute decision making based on nonlinear programming methodology, particle swarm optimization techniques and interval-valued intuitionistic fuzzy values," Information Sciences, vol. 471, pp. 252-268, 2019.

[33] Z. Yang, H. Garg, J. Li, G. Srivastava, and Z. Cao, "Investigation of multiple heterogeneous relationships using a qRung orthopair fuzzy multi-criteria decision algorithm," Neural Computing and Applications, pp. 1-22, 2020.

[34] L. Yang, "Research on development strategies of China's container multimodal transport," Railway Transport and Economy, vol. 38, no. 7, pp. 7-10, 2016.

[35] H. Zhu, H. Yao, and B. Liu, "Study on the construction of evaluation index system of container multimodal transport efficiency," Railway Transport and Economy, vol. 40, no. 5, pp. 8-14, 2018.

[36] Z. Xu and Z. Sun, "The ranking method for a class of uncertain multi-attribute decision-making problems," Journal of Management Science, vol. 2002, no. 3, pp. 35-39, 2002.

[37] H. Lin and P. Shao, "Evaluation and application of online advertising media based on mixed multi-attribute decision," Management Review, vol. 24, no. 12, pp. 53-63, 2012.

[38] Z. Xu, "Multi attribute decision making method based on deviation maximization of degree of separation and possibility," Control and Decision, vol. 16, no. z1, pp. 818-821, 2001.

[39] Z. Xu, "An algorithm for ranking fuzzy complementary judgment matrix," Journal of Systems Engineering, vol. 16, no. 4, pp. 311-314, 2001. 